\title{
The Carbenium Ion-Onium Ion Equilibria in Cationic Polymerization
}

\author{
St. PENCZEK and R. SZYMAŃSKI
}

Polish Academy of Sciences, Center of Molecular and Macromolecular Studies, 90-362 Łódź, Poland.

(Received April 15, 1980)

\begin{abstract}
In the cationic polymerization of vinyl and cyclic monomers containing heteroatoms there is a possibility of simultaneous presence of carbenium and onium ions being in dynamic equilibrium, e.g.,

$$
\ldots-\mathrm{CH}_{2}^{+}+\mathrm{X}_{-\cdots}^{-\cdots} \rightleftharpoons \ldots-\mathrm{CH}_{2} \stackrel{+}{\mathrm{X}} \backslash \ldots
$$

(where $\mathrm{X}$ is a heteroatom)

Fragment containing the heteroatom $\mathrm{X}$ can either come from macromolecule or from monomer itself. Polymerization of cyclic acetals, for which intra- and inter-molecular formation of onium ions has been discussed in detail, was modelled by systems involving both carbenium and oxonium ions, separately observed by ${ }^{1} \mathrm{H}$ NMR. Application of dynamic ${ }^{1} \mathrm{H}$ NMR allowed the rate constants involving both kinds of ions to be determined, and showed, that, at least in the polymerization of 1,3-dioxolane, the macrooxonium ions dominate in the chain growth.
\end{abstract}

KEY WORDS Carbenium Ion/Onium Ion / Carbenium-Onium Equilibria /

Cationic Polymerization / Dynamic ${ }^{1} \mathrm{H}$ NMR /

When monomers containing heteroatoms are polymerized by cationic mechanism, then the carbenium-onium equilibrium has to be taken into account:

$$
\underset{y}{\prime} \mathrm{C}^{+}+\mathrm{X}^{\prime} \rightleftharpoons \stackrel{+}{=} \mathrm{C}-\stackrel{+}{\mathrm{x}}^{\prime}
$$

(where $\mathrm{X}$ is a heteroatom)

Depending on the structure of carbenium ion involved and nucleophilicity of the heteroatom in monomer and/or polymer, the following cases should be considered.

1) Formation of onium ion can be neglected (low reactivity of the carbenium ion, low nucleophilicity of the heteroatom).

2) Both carbenium and onium ions coexist in dynamic equilibrium.

3) Carbenium ions are quantitatively converted into the onium ions (high reactivity of carbenium ion, high nucleophilicity of the heteroatom).
Apparently, the large majority of the real systems belong either to the category 2) or 3). For instance, the cationic ring-opening polymerizations of some cyclic ethers (e.g., THF), cyclic sulphides, or cyclic amines undoubtedly belong to the third category. However, polymerization at least of some cyclic acetals may belong to the second class, because the carbenium ion is already sufficiently stabilized by the adjacent oxygen atom and on the other hand the oxygen atom in the ligands, participating in formation of oxonium ions ( $\mathrm{X}^{+}=$in eq 1$)$, is not a too strong nucleophile.

In the polymerization of vinyl monomers containing heteroatoms the carbenium-onium equilibrium, although possible, has not yet been studied. If we take, however, as an example a vinyl ether, then the following carbenium oxonium equilibrium can be envisaged (e.g., involving polymer segments): 


$$
\cdots-\mathrm{CH}_{2}-\stackrel{+}{\mathrm{C}} \mathrm{O}
$$

Carbenium<smiles>[R]OC(CC)CC</smiles>

\section{Oxonium}

Propagation may now involve both carbenium and oxonium species and the measured effective rate constant of propagation $k_{\mathrm{p}}^{\text {app }}$ should be first broken into the carbenium and oxonium components. This kind of equilibria, if it mostly involves a polymer, would also have an important kinetic effect (e.g., increasing proportion of onium ions with monomer conversion).

In the polymerization of cyclic acetals the propagation involving carbenium ions was postulated many times, but, again, there are no experimental data available for the carbenium-oxonium ion equilibria for these monomers.

The carbenium-onium ion equilibria are also important for the initiation processes, particularly, when this equilibrium is shifted by starting polymerization on the first onium ion and when the hydride-anion transfer processes are competing with the initiation by addition.

In this paper the above-mentioned aspects of the carbenium-onium ion equilibria will be discussed.

First, the available data on equilibria and rates of establishing of these equilibria will be given, then the initiation proceses, based on the carbeniumonium interconversion, will be described and, eventually, the new data on the carbeniumoxonium ion equilibria in cyclic acetals polymerization will be discussed on the basis of the new data, coming from the studies of conversion of carbenium ion into an oxonium ion by the dynamic ${ }^{1} \mathrm{H}$ NMR. The equilibrium constants and the rate constants of interconversions have been determined, by using this technique. These measurements allowed us to estimate for the first time the proportions and relative reactivities of carbenium and oxonium ions in the polymerization of cyclic acetals.

\section{THE CARBENIUM-ONIUM ION INTERCONVERSIONS EQUILIBRIA}

Recently Hiraoka and Kebarle have determined the equilibrium constant for the reaction of $t-\mathrm{C}_{4} \mathrm{H}_{9}{ }^{+}$ with $\mathrm{H}_{2} \mathrm{O}$ in the gas phase, ${ }^{1}$ and found the following thermodynamic parameters: $\Delta H=-11.2 \mathrm{kcal}$ $\mathrm{mol}^{-1}$ and $\Delta S=-22 \mathrm{cal} \mathrm{mol}^{-1} \mathrm{deg}^{-1}$ :

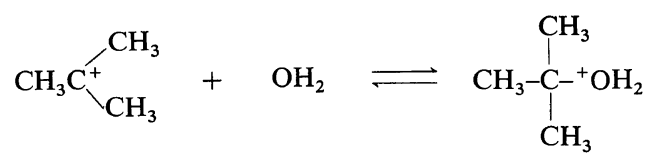

It has to be noted that the addition of further molecules of $\mathrm{H}_{2} \mathrm{O}$ to the oxonium ion is even more exothermic. ${ }^{1}$

Due to the $\mathrm{I}^{+}$effect of the methyl groups and resulting stabilization of the $t-\mathrm{C}_{4} \mathrm{H}_{9}{ }^{+}$cation, the heat of oxonium ion formation is much lower than for the secondary, and, particularly, primary carbenium ions. The corresponding heats of conversion of these carbenium ions into the oxonium ions in reaction with $\mathrm{H}_{2} \mathrm{O}$ are given below. ${ }^{1}$

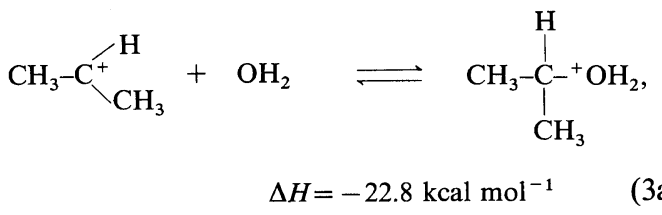

and

$$
\begin{array}{r}
\mathrm{CH}_{3}{ }^{+}+\mathrm{OH}_{2} \rightleftharpoons \mathrm{CH}_{3}-^{+} \mathrm{O}_{{ }_{\mathrm{H}}}^{-\mathrm{H}}, \\
\Delta H=-66 \mathrm{kcal} \mathrm{mol}^{-1}
\end{array}
$$

The data for the dimethylmethylium and methylium cations were calculated from the heats of formation of carbenium ions and corresponding bases and proton affinities of the bases. ${ }^{1}$

Heats measured in solution may substantially differ from the heats found for the gas phase, especially in solvents sufficiently nucleophilic to interact specifically with carbenium ions.

The first comprehensive measurements of the carbenium-oxonium ion equilibria involving triphenylmethylium cation in solvents unable to form the onium ions by themselves were reported from our laboratory for a number of linear and cyclic 
Table I. Equilibrium constants and thermodynamic parameters for the carbenium-oxonium ion equilibria involving the triphenylmethylium cation ${ }^{2}$ :

$$
\left(\mathrm{C}_{6} \mathrm{H}_{6}\right)_{3} \mathrm{C}^{+}+\mathrm{O}^{\prime} \frac{K_{\mathrm{e}}}{\underset{\mathrm{CH}_{2} \mathrm{Cl}_{2}}{\rightleftharpoons}}\left(\mathrm{C}_{6} \mathrm{H}_{5}\right)_{3} \mathrm{C}^{+}{ }^{+} \mathrm{O}^{\prime}
$$

\begin{tabular}{|c|c|c|c|c|}
\hline \multirow{2}{*}{ Nucleophile } & \multicolumn{2}{|c|}{$K_{\mathrm{e}} / \mathrm{mol}^{-1} 1^{-1}$} & \multirow{2}{*}{$\frac{\Delta H_{\mathrm{e}}}{\mathrm{kcal} \mathrm{mol}^{-1}}$} & $\Delta S_{\mathrm{e}}$ \\
\hline & $25^{\circ} \mathrm{C}$ & $-73^{\circ} \mathrm{C}$ & & cal $\mathrm{mol}^{-1} \mathrm{deg}^{-1}$ \\
\hline $\mathrm{H}_{2} \mathrm{O}$ & $6.2 \times 10^{1}$ & $1.4 \times 10^{5}$ & $-9.3 \pm 0.3$ & $-23 \pm 1$ \\
\hline THF & $1.6 \times 10^{0}$ & $1.8 \times 10^{5}$ & $-14 \pm 1$ & $-46 \pm 3$ \\
\hline$\left(\mathrm{C}_{2} \mathrm{H}_{5}\right)_{2} \mathrm{O}$ & $2.3 \times 10^{-1}$ & $2.9 \times 10^{5}$ & $-17 \pm 3$ & $-60 \pm 5$ \\
\hline $\mathrm{DXL}^{\mathrm{b}}$ & $6.4 \times 10^{-2 a}$ & $2.6 \times 10^{1 \mathrm{a}}$ & $7.3 \pm 0.6$ & $-30 \pm 2^{a}$ \\
\hline$\left(\mathrm{CH}_{3} \mathrm{O}\right)_{2} \mathrm{CH}_{2}$ & $4.4 \times 10^{-2 a}$ & $4.4 \times 10^{1 \mathrm{a}}$ & $-8.3 \pm 0.2$ & $-34 \pm 1^{\mathrm{a}}$ \\
\hline
\end{tabular}

a In ref 2, values of $K_{\mathrm{e}}$ are corrected for a symmetry number.

b 1,3-Dioxolane.

ethers and acetals. ${ }^{2}$ These data were partially discussed already at the 4th Cationic Meeting in Rouen. ${ }^{3}$ Before, in Table I some of the pertinent data are listed again. These will be needed in further discussion of the addition-transfer competition in the initiation processes, as well as in further discussion of the carbenium-oxonium equilibria in cyclic acetals.

The data presented in Table I are taken from the much more extensive collection given in ref 2 , and few comparisons, relevant for the polymerization of cyclic ethers and acetals, can be made on its basis. First of all it should be noted, according to expectations based on the measurements of basicities $^{4}$ that, particularly at the lower temperatures, ethers are much more powerful oxonium-forming compounds than acetals (the difference being up to $10^{4}$ times between THF and DXL). Secondly, the cyclic and linear acetals have almost similar oxonium-forming ability. Eventually, remembering the role water is playing in cationic polymerization, it can be noted, that $\mathrm{H}_{2} \mathrm{O}$ is comparable (at least when $\left(\mathrm{C}_{6} \mathrm{H}_{5}\right)_{3} \mathrm{C}^{+}$cation is concerned) with $\mathrm{THF}$ and $\left(\mathrm{C}_{2} \mathrm{H}_{5}\right)_{2} \mathrm{O}$ but much more powerful a nucleophile than both DXL and dimethoxymethane.

More recently similar studies were extended by Bjorøy to aromatic phosphines. ${ }^{5}$ ( $c f$. Table II)

Thus, the difference between equilibrium constants for the formation of oxonium and phosphonium ions is from $10^{7}$ to $10^{9}$ times. Therefore, addition of even small amounts of phosphines into the polymerizing systems with oxonium ions as

Table II. Equilibrium constants and thermodynamic parameters for the carbenium-phosphonium ion equilibria involving the triphenylmethylium cation:

$$
\left(\mathrm{C}_{6} \mathrm{H}_{5}\right)_{3} \mathrm{C}^{+}+\mathrm{P} \leftarrow \stackrel{K_{\mathrm{e}}}{\rightleftharpoons}\left(\mathrm{C}_{6} \mathrm{H}_{5}\right)_{3} \mathrm{C}-\stackrel{+}{\mathrm{P}} \div
$$

\begin{tabular}{lcccc}
\hline \multirow{2}{*}{ Nucleophile } & Solvent & $K_{\mathrm{e}} / \mathrm{mol} \mathrm{l}^{-1}$ & $\Delta H_{\mathrm{e}}$ & $\Delta S_{\mathrm{e}}$ \\
\cline { 3 - 5 } & & $25^{\circ} \mathrm{C}$ & $\mathrm{kcal} \mathrm{mol}^{-1}$ & $\mathrm{cal} \mathrm{mol}^{-1} \mathrm{deg}^{-1}$ \\
\hline \multirow{2}{*}{$\left(\mathrm{C}_{6} \mathrm{H}_{5}\right)_{3} \mathrm{P}$} & $\mathrm{CH}_{3} \mathrm{CN}$ & $7.1 \times 10^{7}$ & -19.2 & -29 \\
& $\mathrm{CH}_{2} \mathrm{Cl}_{2}$ & $1.6 \times 10^{7}$ & -12.6 & -10 \\
& & & & - \\
\hline
\end{tabular}


active species, results in converting the oxonium ions into the much more stable phosphonium ions $^{6,7}$ :

$$
\begin{aligned}
& \text { e.g., } \cdots-\mathrm{O}\left(\mathrm{CH}_{2}\right)_{4} \mathrm{O}-\underset{\mathrm{CH}_{2} \mathrm{CH}_{2}}{-\mathrm{CH}_{2} \mathrm{CH}_{2}}+\mathrm{P}\left(\mathrm{C}_{6} \mathrm{H}_{5}\right)_{3} \longrightarrow \\
& \cdots-\mathrm{O}\left(\mathrm{CH}_{2}\right)_{4} \stackrel{+}{\mathrm{P}}\left(\mathrm{C}_{6} \mathrm{H}_{5}\right)_{3}
\end{aligned}
$$

or

$$
\begin{gathered}
\cdots-\mathrm{OCH}_{2} \mathrm{CH}_{2} \mathrm{OCH}_{2} \stackrel{+}{\mathrm{O}^{\prime}} \backslash \\
{[\operatorname{poly}(\mathrm{DXL})]}
\end{gathered}
$$$$
\cdots-\mathrm{OCH}_{2} \mathrm{CH}_{2} \mathrm{OCH}_{2} \stackrel{+}{\mathrm{P}}\left(\mathrm{C}_{6} \mathrm{H}_{5}\right)_{3}
$$

Although both reactions 4 and 5 are shifted very much to the right-hand side, in order to stop polymerization one has to use either the sufficiently high excess of phosphine or the most nucleophilic phosphines. For instance, a twofold excess of ( $n$ $\mathrm{Bu})_{3} \mathrm{P}$ over stochiometry (compared with a concentration of active species) practically stops at $25^{\circ} \mathrm{C}$ polymerization of DXL and THF initiated by carbenium ions or protonic acids. However, polymerization of DXL, initiated with $\mathrm{CF}_{3} \mathrm{SO}_{3} \mathrm{H}$ cannot be stopped by the same excess of $\left(\mathrm{C}_{6} \mathrm{H}_{5}\right)_{3} \mathrm{P}$. The tertiary phosphonium ion, formed by trapping a proton from the secondary oxonium ion, is not sufficiently stable, and in the equilibrium, e.g.,

$$
\begin{aligned}
\stackrel{+}{\mathrm{H}-\stackrel{+}{\mathrm{O}} \mathrm{O}}+\stackrel{\mathrm{P}\left(\mathrm{C}_{6} \mathrm{H}_{5}\right)_{3}}{\rightleftharpoons} \\
\stackrel{\Gamma_{\mathrm{O}} \mathrm{O}}{\rightleftharpoons}+{ }_{\mathrm{H}-\stackrel{+}{\mathrm{P}}\left(\mathrm{C}_{6} \mathrm{H}_{5}\right)_{3}}
\end{aligned}
$$

there is enough of the secondary oxonium ions to restart polymerization (the position of equilibrium (6) has not however, been measured).

\section{THE CARBENIUM-ONIUM ION INTERCONVERSIONS. THE RATES}

\section{Rates of Associations}

Dorfman used the pulse-radiolysis method for determination of the rate constants of onium ions formation from various carbenium ions, including phenylmethylium cation and triphenylmethylium cation..$^{8,9,12}$ The rate constants of reactions of three
Table III. Rate constants of reactions of carbenium ions with tertiary amines: ${ }^{8}$

\begin{tabular}{lccc}
\multicolumn{4}{c}{$\mathrm{R}^{+}+\mathrm{NR}_{3}^{\prime} \stackrel{k_{\mathrm{a}}}{\longrightarrow} \mathrm{R}-{ }^{+} \mathrm{NR}_{3}^{\prime}$} \\
\hline $\begin{array}{c}\text { Nucleophile } \\
\mathrm{R}^{+}\end{array}$ & $k_{\mathrm{a}} / 1 \mathrm{~mol}^{-1} \mathrm{~s}^{-1} ; \quad \mathrm{CH}_{2} \mathrm{Cl}_{2}, 24^{\circ} \mathrm{C}$ \\
\cline { 2 - 4 } & $\mathrm{C}_{6} \mathrm{H}_{5} \mathrm{CH}_{2}^{+}$ & $\left(\mathrm{C}_{6} \mathrm{H}_{5}\right)_{2} \mathrm{CH}^{+}$ & $\left(\mathrm{C}_{6} \mathrm{H}_{5}\right)_{3} \mathrm{C}^{\prime+}$ \\
\hline$\left(\mathrm{C}_{2} \mathrm{H}_{5}\right)_{3} \mathrm{~N}$ & $2.8 \times 10^{9}$ & $2.9 \times 10^{9}$ & $1.5 \times 10^{8}$ \\
$\left(n-\mathrm{C}_{3} \mathrm{H}_{7}\right)_{3} \mathrm{~N}$ & $2.6 \times 10^{9}$ & $1.5 \times 10^{9}$ & $4.5 \times 10^{7}$ \\
$\left(n-\mathrm{C}_{4} \mathrm{H}_{9}\right)_{3} \mathrm{~N}$ & $2.4 \times 10^{9}$ & $1.1 \times 10^{9}$ & $9.2 \times 10^{8}$ \\
\hline
\end{tabular}

different carbenium ions with tertiary amines as nucleophiles are given in Table III.

Thus, almost all of the pairs listed in Table III react with the rate constants close to those characteristic for the diffusion-controlled reactions.

Changing of the nucleophile does not influence too much the rate constants, unless enough of the steric hindrance is built up. Thus, in the reaction of $\mathrm{C}_{6} \mathrm{H}_{5} \mathrm{CH}_{2}{ }^{+}$cation with various nucleophiles in $\left(\mathrm{CH}_{2} \mathrm{Cl}\right)_{2}$ solvent at $25^{\circ} \mathrm{C}$ the following $k_{\mathrm{a}}$ were measured $^{9}: \quad\left(\mathrm{C}_{2} \mathrm{H}_{5}\right)_{3} \mathrm{P} \quad\left(8.1 \times 10^{9}\right) ; \quad\left(\mathrm{C}_{2} \mathrm{H}_{5}\right)_{3} \mathrm{As}$ $\left(2.2 \times 10^{9}\right) ; \mathrm{NH}_{3}\left(4.2 \times 10^{9}\right)$.

Values lower $10^{2}$ times were found for $\mathrm{H}_{2} \mathrm{O}$ and $\mathrm{CH}_{3} \mathrm{OH}$. Rate constants as low as $10^{2} 1 \mathrm{~mol}^{-1} \mathrm{~s}^{-1}$ were observed by Kim and Leffek ${ }^{10}$ for the sterically hindered reactions; e.g., between triphenylmethylium cation and 2,6-dimethylpyridine.

\section{Rates of Dissociation of Onium Ions into Constituents}

In this section we shall discuss the available data on the rate constants of reverse reaction, namely formation of carbenium ions from oxonium ions, confining again ourselves to measurements made in non-aqueous solutions. The large body of information has been provided by Olah in superacid (e.g., $\mathrm{HSO}_{3} \mathrm{~F}-\mathrm{SbF}_{5}$ ) solutions. ${ }^{11}$ The presence of $\mathrm{SbF}_{5}$, provides a strong electrophile in the system, which can react with the nucleophilic sites, competing in this way with carbenium ions. This makes these data difficult to compare with the rate constants of association, discussed in the previous paragraph.

The rates of dissociation can be, however, estimated, at least for triphenylmethylium cation, on the basis of measurements of the rate constants of association and equilibrium constants. For one 
Ion Equilibria in Cationic Polymerization

system the rate of dissociation was measured: Dorfman gives for $\left(n-\mathrm{C}_{4} \mathrm{H}_{9}\right)_{3} \mathrm{~N} k_{\mathrm{d}} \sim 4 \times 10^{4} \mathrm{~s}^{-1}$ :

$$
\begin{array}{r}
\left(\mathrm{C}_{6} \mathrm{H}_{5}\right)_{3} \mathrm{C}^{+}+\mathrm{N}\left(n-\mathrm{C}_{4} \mathrm{H}_{9}\right)_{3} \stackrel{k_{\mathrm{a}}}{\underset{k_{\mathrm{d}}}{\rightleftharpoons}} \\
\left(\mathrm{C}_{6} \mathrm{H}_{5}\right)_{3} \mathrm{C}-\stackrel{+}{\mathrm{N}}\left(n-\mathrm{C}_{4} \mathrm{H}_{9}\right)_{3}
\end{array}
$$

However, $K_{\mathrm{e}}$ in this case is equal only to $2 \times 10^{2}$ $\mathrm{mol}^{-1} 1,{ }^{12}$ and this seems to be too low, when compared with values reported for phosphines (Table II).

The comparison of the date from Table I (e.g., for $\mathrm{H}_{2} \mathrm{O}$ ) with $k_{\mathrm{a}}$ measured for the same nucleophiles leads to conclusion, that the rate constants of dissociation are high for stronger oxygen containing nucleophiles $\left(\mathrm{H}_{2} \mathrm{O}\right.$, THF) and even higher for the weaker ones (acetals). Here, again ( $c f$. Introduction) the rate constants will depend on the reactivity of the carbenium ion (primary $>$ secondary $>$ tertirary) and nucleophilicity of the nucleophilic component of the onium ion. For instance, the phosphonium ions, e.g., formed in ion-trapping with $\left(n-\mathrm{C}_{4} \mathrm{H}_{9}\right)_{3} \mathrm{P}$ in the polymerization of THF, i.e.:

$$
\cdots-\mathrm{OCH}_{2} \mathrm{CH}_{2} \mathrm{CH}_{2} \mathrm{CH}_{2} \stackrel{+}{\mathrm{P}}\left(n-\mathrm{C}_{4} \mathrm{H}_{9}\right)_{3}
$$

are sufficiently stable to withstand hydrolysis in water for several hours without an appreciate dissociation.

\section{THE CARBENIUM-ONIUM ION EQUILIBRIA IN THE INITIATION PROCESSES}

Carbenium ions react with nucleophiles containing heteroatoms not only by addition, leading to the onium ions, but also by abstracting the $\mathrm{H}^{-}$ anion. Meerwein studied the $\mathrm{H}^{-}$transfer reactions for a number of oxygen containing compounds, including cyclic ethers and acetals. ${ }^{13}$ The first extensive kinetic data on $\mathrm{H}^{-}$transfer came from our laboratory, ${ }^{14}$ followed by measurements made in other laboratories. ${ }^{15,16}$ These $\mathrm{H}^{-}$transfer reactions are upsetting the otherwise clean initiation by addition. As it already has been mentioned, we formulated a general scheme of initiation including both addition and transfer processes ${ }^{3}$ :

(e.g., for $\left(\mathrm{C}_{6} \mathrm{H}_{5}\right)_{3} \mathrm{C}^{+}$and DXL):

$$
\begin{aligned}
& \left(\mathrm{C}_{6} \mathrm{H}_{5}\right)_{3} \mathrm{C}^{+}+{ }_{\mathrm{O}} \frac{k_{\mathrm{a}}}{\underset{k_{\mathrm{d}}}{\rightleftarrows}}
\end{aligned}
$$

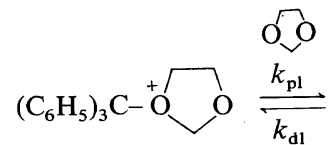

$$
\begin{aligned}
& \left(\mathrm{C}_{6} \mathrm{H}_{5}\right)_{3} \mathrm{C}-\mathrm{O} \mathrm{O} \sqrt[+]{\mathrm{O}} \\
& \left(\mathrm{C}_{6} \mathrm{H}_{5}\right)_{3} \mathrm{C}^{+}+\mathrm{O} \mathrm{O} \underset{k_{-\mathrm{H}^{-}}}{\stackrel{k_{\mathrm{H}}{ }^{-}}{\rightleftarrows}} \\
& \left(\mathrm{C}_{6} \mathrm{H}_{5}\right)_{3} \mathrm{CH}+\underset{\mathrm{H}}{\mathrm{O}_{\ldots}^{+} \mathrm{O}}
\end{aligned}
$$

It follows from the analysis of the scheme 7 , that in order to have a large proportion of initiation by addition (route involving $k_{\mathrm{a}}$ and $k_{\mathrm{pl}}$ ), both $k_{\mathrm{a}}$ and $k_{\mathrm{pl}}$ should be high in comparison with other rate constants, and particularly $k_{\mathrm{H}-}$ and $k_{\mathrm{d}}$ (the $\mathrm{H}^{-}$ transfer does not proceed as a $\mathrm{H}^{-}$shift intramolecularly, within the onium ions). On our opinion this is mostly the steric hindrance, that does not permit the reaction with $k_{\mathrm{pl}}$ to proceed with a sufficiently high rate. This is apparently the case of the bulky triphenylmethylium cation and "large" and not very strained THF and DXL.

Recently it has been shown, that diphenylmethylium cation initiates polymerization of THF exclusively by addition ${ }^{17}$ :
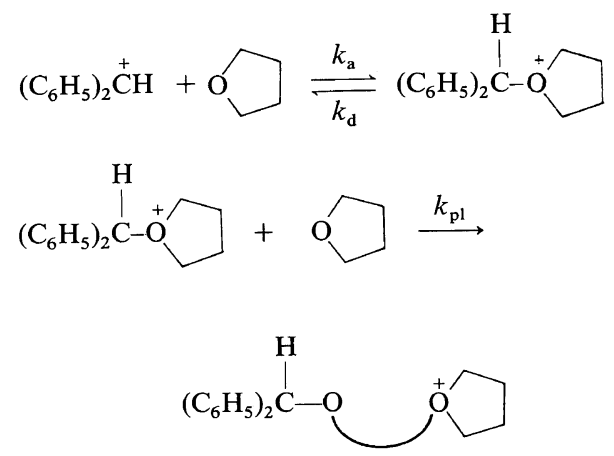

Apparently, as we proposed in scheme 7, the steric hindrance, preventing the triphenylmethylium cation, bearing the first monomer molecules, to add the second one $\left(k_{\mathrm{pl}}\right)$, is reduced to the degree, that the second monomer molecule addition competes 
successfully with a $\mathrm{H}^{-}$transfer. It has also to be remembered that the proportion of oxonium ions in equilibrium with their carbenium counterparts

$$
\left.\left.\left[\left(\mathrm{C}_{6} \mathrm{H}_{5}\right)_{2} \mathrm{CH}-\stackrel{+}{\mathrm{O}}\right]\right] /\left[\left(\mathrm{C}_{6} \mathrm{H}_{5}\right)_{2} \stackrel{+}{\mathrm{C}} \mathrm{H}\right]\right)
$$

should also be higher for diphenylmethylium cation than for triphenylmethylium cation. This also increases the probability of initiation by addition.

\section{THE CARBENIUM-ONIUM ION EQUILIBRIA IN THE PROPAGATION PROCESSES}

Let us consider a system, in which propagation can proceed on both carbenium and oxonium ions being in dynamic equilibrium. As it has already been discussed, from all of the ring-opening polymerizations these are the cyclic acetals, that are the most likely to propagate on these two kinds of active species. Thus, for, e.g., 1,3-dioxolane we can have:
For such reaction scheme 10, the equilibrium between the carbenium and oxonium growing species has to be established faster than the monomer addition to any of the two growing species $\left(k_{\mathrm{a}}, k_{\mathrm{d}}>k_{\mathrm{pc}}, k_{\mathrm{pox}}\right)$. Moreover, the rearrangement of the monomer holding oxonium ion into the carbenium ion has also to be faster than the monomer addition $\left(k_{\mathrm{p}}^{\prime}>k_{\mathrm{pc}} \cdot[\mathrm{DXL}], k_{\mathrm{pox}} \cdot[\mathrm{DXL}]\right)$ in order to conform to the second-order kinetics observed in the polymerization of DXL.

\section{Model Studies of the Reactivities of Carbenium and Oxonium Ions ${ }^{18}$}

This section is based on our recent work, in which the following systems have been studied.

$$
\begin{aligned}
& \mathrm{CH}_{3} \stackrel{+}{C}^{\mathrm{H}}{ }_{2}+\mathrm{O}^{\prime} \frac{k_{\mathrm{a}}}{\underset{k_{\mathrm{d}}}{\rightleftharpoons}} \mathrm{CH}_{3} \mathrm{OCH}_{2} \stackrel{+}{\mathrm{O}} \\
& \underbrace{\mathrm{CH}_{3} \mathrm{OCH}_{2} \stackrel{+}{\mathrm{O}} \backslash}+\underset{\mathrm{O}^{\prime}}{\stackrel{k_{\mathrm{e}}}{\rightleftharpoons}} \\
& \mathrm{CH}_{3} \mathrm{OCH}_{2} \mathrm{O}_{-}^{+}+\mathrm{O}^{\prime}
\end{aligned}
$$

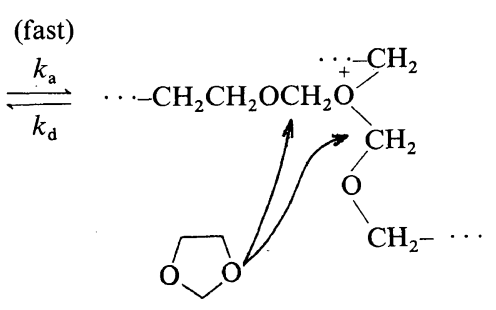

$$
\begin{aligned}
& k_{\mathrm{pc}} . \int k_{\mathrm{dc}} \quad k_{\mathrm{pox}} / / k_{\mathrm{dox}} \\
& \cdots-\mathrm{CH}_{2} \mathrm{CH}_{2} \mathrm{OCH}_{2}+\stackrel{+}{\mathrm{O}} \\
& k_{\mathrm{p}}^{\prime} \downarrow \text { (fast) } \\
& \text {-..- }-\mathrm{CH}_{2} \mathrm{CH}_{2} \mathrm{O}^{\mathrm{C}} \mathrm{H}_{2}
\end{aligned}
$$

Comparison of scheme 10 with reactions $11 \mathrm{a}$ and b shows that they can be used to estimate not only the proportions of carbenium and oxonium ions but in addition the reactivities of both kinds of involved ions. This comparison requires the simultaneous determination of $k_{\mathrm{a}}, k_{\mathrm{d}}$, and $k_{\mathrm{e}}$.

We shall confine ourselves in this review to two model systems, namely $\mathrm{CH}_{3} \mathrm{O}^{+} \mathrm{CH}_{2}+\mathrm{O}\left(\mathrm{CH}_{3}\right)_{2}$ and $\mathrm{CH}_{3} \mathrm{O}^{+} \mathrm{CH}_{2}+\mathrm{CH}_{2}\left(\mathrm{OCH}_{3}\right)_{2}$, the experimental de- tails being given elsewhere. ${ }^{18}$ The methoxycarbenium hexafluoroantimonate or chloropentafluoroantimonate were used throughout this work all of the measurements being made in $\mathrm{SO}_{2}$ solvent by using ${ }^{1} \mathrm{H}$ NMR.

When the excess of one of the reagents is used at $-70^{\circ} \mathrm{C}$ in $\mathrm{SO}_{2}$ solution:

e.g., 
<smiles>C=C(COC)COC</smiles>

then only this reagent and the product-oxonium ion are seen in ${ }^{1} \mathrm{H}$ NMR. The rate of exchange is sufficiently low to permit to see separately both cations.

${ }^{1} \mathrm{H}$ NMR spectrum of $\mathrm{CH}_{3} \mathrm{O} \stackrel{+}{\mathrm{C}} \mathrm{H}_{2}$ (anions omitted in further text), and of the oxonium salt involving dimethyl ether is characterized below $\left(-70^{\circ} \mathrm{C}, \mathrm{SO}_{2}\right.$ solvent, concentrations close to $10^{-2} \mathrm{~mol}^{-1}$ ):

$$
\begin{array}{cc}
\mathrm{CH}_{3} \mathrm{O} \stackrel{+}{\mathrm{C}} \mathrm{H}_{2} & \mathrm{CH}_{3} \mathrm{OCH}_{2} \stackrel{+}{\mathrm{O}}-\mathrm{CH}_{3} \\
\delta 5.2(\mathrm{~s}) \text { and } & \delta 3.81(\mathrm{~s}), 5.7 \text { (s), and } \\
9.5(\mathrm{~s}) \mathrm{ppm} & 4.25(\mathrm{~s}) \mathrm{ppm}
\end{array}
$$

(chemical shifts slightly depend on concentrations and temperatures)

At higher temperature the signals broaden, and eventually the coalescence is observed. Nevertheless, the spectra are fully reversible and cooling down the mixture giving the coalesced spectrum restores in detail, without additional signals, the original spectrum of 12a and 12c. When the dimethyl ether (12b) is taken in excess, only $\mathbf{1 2 b}$ and $\mathbf{1 2 c}$ are seen in ${ }^{1} \mathrm{H}$ NMR spectrum at $-70^{\circ} \mathrm{C}$. At the equimolar mixture of $12 \mathrm{a}$ and $12 \mathrm{~b}$ only the signals due to $12 \mathrm{c}$ are observed at $-70^{\circ} \mathrm{C}$.

Chemical shifts of protons in $12 \mathrm{c}$ slightly depend on the reagents concentrations and temperature.

At the equimolar mixture exchange between the components of the system becomes apparent, and the positions of the corresponding chemical shifts become the weighed averages of the concentrations and chemical shifts of the involved protons. Thus, rewriting again the equilibrium 12 we have the following exchanging groups:

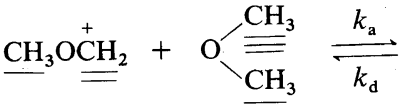

$$
\begin{aligned}
& \text { 12a } \overline{\overline{12 b}}
\end{aligned}
$$

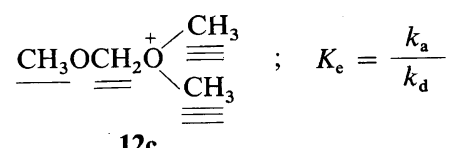

There are three groups of exchanging group, and, thus, at the conditions of fast exchange only three singlets are observed. Denoting for the corresponding exchanging groups: $\delta_{1}\left(\mathrm{CH}_{3} \mathrm{O}\right), \delta_{2}\left(\mathrm{OCH}_{2}\right)$, and $\delta_{3}\left(\mathrm{OCH}_{3}\right)$ we have for the observed chemical shifts $\delta_{1}, \delta_{2}$, and $\delta_{3}$ :

$$
\begin{aligned}
& \delta_{1}=\delta_{1 \mathrm{a}} \frac{[12 \mathrm{a}]}{[12 \mathrm{a}]+[12 \mathrm{c}]}+\delta_{1 \mathrm{c}} \frac{[12 \mathrm{c}]}{[12 \mathrm{a}]+[12 \mathrm{c}]} \\
& \delta_{2}=\delta_{2 \mathrm{a}} \frac{[12 \mathrm{a}]}{[12 \mathrm{a}]+[12 \mathrm{c}]}+\delta_{2 \mathrm{c}} \frac{[12 \mathrm{c}]}{[12 \mathrm{a}]+[12 \mathrm{c}]} \\
& \delta_{3}=\delta_{3 \mathrm{~b}} \frac{[12 \mathrm{~b}]}{[12 \mathrm{~b}]+[12 \mathrm{c}]}+\delta_{3 \mathrm{c}} \frac{[12 \mathrm{c}]}{[12 \mathrm{~b}]+[12 \mathrm{c}]}
\end{aligned}
$$

Since

$$
K_{\mathrm{e}}=\frac{[12 \mathrm{c}]}{[12 \mathrm{a}][12 \mathrm{~b}]}
$$

then, for $[12 a]=[12 b]$, we have

$$
[12 \mathrm{a}]=[12 \mathrm{~b}]=K_{\mathrm{e}}^{1 / 2}[12 \mathrm{c}]^{1 / 2}
$$

From eq $13^{\prime}, 13^{\prime \prime}$, and 14 we have eventually:

$$
K_{\mathrm{e}}=\frac{1}{[12 \mathrm{c}]}\left|\frac{\left(\delta_{2 \mathrm{a}}-\delta_{3 \mathrm{~b}}\right)-\left(\delta_{2}-\delta_{3}\right)}{\left(\delta_{2}-\delta_{3}\right)-\left(\delta_{2 \mathrm{c}}-\delta_{3 \mathrm{c}}\right)}\right|^{2}
$$

Chemical shifts $\delta_{1}$ and $\delta_{2}$ are taken directly from the ${ }^{1} \mathrm{H}$ NMR spectrum of equimolar mixture of 12a and $12 \mathrm{~b}$ for the given temperature, whereas $\delta_{2 \mathrm{a}}, \delta_{2 \mathrm{c}}$ and $\delta_{3 \mathrm{~b}}, \delta_{3 \mathrm{c}}$ are determined for every temperature in the independent series of measurements, and for the concentration being used for studies of equilibria. Since the equilibrium is shifted substantially to the side of oxonium ion we take [12c] as equal to the concentration of substrates.

Below, average values of $K_{\mathrm{e}}$, determined at several temperatures and two different concentrations of substrates are given.

\begin{tabular}{cc}
\hline $\mathrm{Temp} /{ }^{\circ} \mathrm{C}$ & $K_{\mathrm{e}} / 1 \mathrm{~mol}^{-1}$ \\
\hline-70 & $2.6 \times 10^{6}$ \\
-50 & $3.4 \times 10^{5}$ \\
-30 & $6.8 \times 10^{4}$ \\
-10 & $1.6 \times 10^{4}$ \\
\hline
\end{tabular}

The dependence of $K_{\mathrm{e}}$ on temperature gives $\Delta H_{\mathrm{e}}=-9.0 \pm 0.7 \mathrm{kcal} \mathrm{mol}^{-1}$ and $\Delta S_{\mathrm{e}}=-15 \pm 3 \mathrm{cal}$ $\mathrm{mol}^{-1} \mathrm{deg}^{-1}$.

The equilibrium constants $K_{\mathrm{e}}$ have also been 
determined for two other ethers, methyl 2chloroethyl ether $\left(K_{\mathrm{em}}\right)$ and di-2-chloroethyl ether $\left(K_{\mathrm{ec}}\right)$. At $-70^{\circ} \mathrm{C}$ the constants are equal to: $6 \times 10^{3}$ and $1.8 \times 10^{2} 1 \mathrm{~mol}^{-1}$ respectively.

The dynamic ${ }^{1} \mathrm{H}$ NMR method has also been used in determination of $K_{\mathrm{e}}$ and the corresponding thermodynamic parameters for equilibrium involving dimethoxymethane:

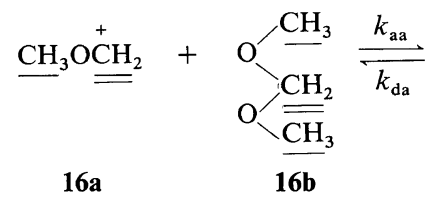

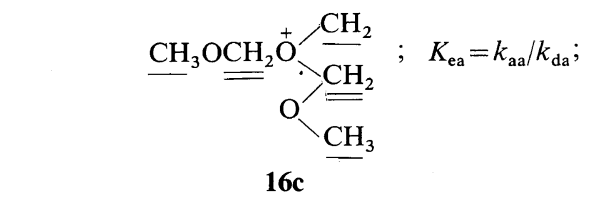

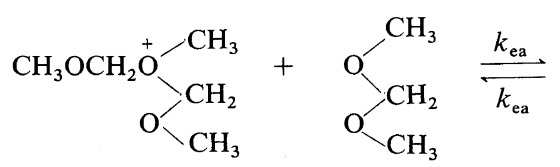

$$
\begin{aligned}
& \mathrm{CH}_{\mathrm{CH}_{3}}^{\mathrm{CH}_{3} \mathrm{OCH}_{2} \mathrm{O}} \stackrel{\mathrm{OH}_{\mathrm{CH}_{3}}}{\mathrm{CH}_{3}}
\end{aligned}
$$

${ }^{1} \mathrm{H}$ NMR spectra of a mixture of methoxycarbenium ion and dimethoxymethane consists in the $-10^{\circ} \mathrm{C}$ to $-70^{\circ} \mathrm{C}$ temperature range exclusively of two singlets. This indicates fast exchange between all of the three compounds involved. Unfortunately, the direct method of determination of the equilibrium constants $K_{\text {ea }}$ could not be used (like in the case of dimethyl ether), because the chemical shifts of the protons involved in the oxonium ion could not be determined. Thus a comparative method has been applied.

Dimethoxymethane and methyl 2-chloroethyl ether were mixed with methoxymethylium cation and the ratio of the equilibrium constants was determined for these two compounds, from which the equilibrium constants for dimethoxymethane was calculated.

Determination of the ratio of equilibrium constants $K_{\text {ea }} / K_{\text {em }}$ is based on the observed by ${ }^{1} \mathrm{H}$ NMR competion between dimethoxymethane and methyl 2-chloroethyl ether in their reaction with methoxycarbenium ion. In other words, since $K_{\mathrm{em}}$ is known, one may find from the ${ }^{1} \mathrm{H}$ NMR spectra the proportion of the methoxymethylium cation involved in the oxonium ion with dimethoxymethane.

Thus, we have the following equilibria.

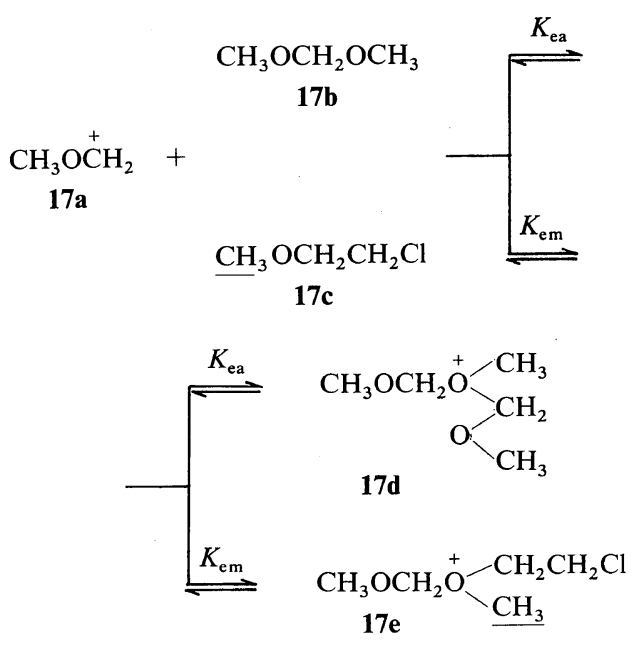

In order to determine $K_{\mathrm{ea}}\left(K_{\mathrm{em}}\right.$ is known, as indicated above, from independent measurements) concentrations of $17 \mathbf{a}, \mathbf{1 7} \mathbf{b}$, and $17 \mathbf{d}$ have to be known.

$$
K_{\text {ea }}=\frac{[17 d]}{[17 \mathbf{a}][17 \mathbf{b}]}
$$

\section{a. Determination of $\left[\mathrm{CH}_{3} \mathrm{O}^{\mathrm{C}} \mathrm{H}_{2}\right]=[17 \mathrm{a}]$}

First [17a] was determined from equilibrium involving 17c and 17e and by using chemical shifts $(\delta)$ of the underlined methyl groups $\mathrm{CH}_{3}-\mathrm{O}$, exchanging between only two compounds, namely $17 \mathrm{c}\left(\delta_{\mathrm{c}}\right)$ and $17 \mathrm{e}\left(\delta_{\mathrm{e}}\right)$.

$$
\delta=\delta_{\mathrm{c}} \frac{[17 \mathrm{c}]}{[17 \mathrm{c}]+[17 \mathrm{e}]}+\delta_{\mathrm{e}} \frac{[17 \mathrm{e}]}{[17 \mathrm{c}]+[17 \mathrm{e}]}
$$

After rearrangement we have

$$
\begin{gathered}
\frac{[17 \mathrm{e}]}{[17 \mathrm{c}]}=\frac{\delta-\delta_{\mathrm{c}}}{\delta_{\mathrm{e}}-\delta} ; \\
\operatorname{or}(+1) \frac{[17 \mathrm{e}]+[17 \mathrm{c}]}{[17 \mathrm{c}]}=\frac{\delta_{\mathrm{e}}-\delta_{\mathrm{c}}}{\delta_{\mathrm{e}}-\delta}=\frac{[17 \mathrm{c}]_{0}}{[17 \mathrm{c}]}
\end{gathered}
$$

Thus

$$
[17 \mathrm{c}]=[17 \mathrm{c}]_{0} \frac{\delta_{\mathrm{e}}-\delta}{\delta_{\mathrm{e}}-\delta_{\mathrm{c}}} ;
$$


Table IV. Determination of $K_{\mathrm{ea}}$ from data on simultaneous measurements of equilibria involving methoxycarbenium ion, methyl 2-chloroethyl ether and dimethoxymethane (eq 17)

\begin{tabular}{|c|c|c|c|c|c|}
\hline \multirow{2}{*}{$\mathrm{Temp} /{ }^{\circ} \mathrm{C}$} & {$[\mathrm{a}]^{\mathrm{a}}$} & {$[\mathrm{b}]^{\mathrm{a}}$} & {$[c]^{\mathrm{a}}$} & $\delta^{\mathbf{b}}$ & \multirow{2}{*}{$K_{\mathrm{ea}}^{\mathrm{c}}$} \\
\hline & $\mathrm{mol} \mathrm{1}^{-1}$ & $\mathrm{~mol} \mathrm{l}^{-1}$ & $\operatorname{mol~1} 1^{-1}$ & ppm & \\
\hline-70 & $8.05 \times 10^{-4}$ & $5.07 \times 10^{-3}$ & $1.3 \times 10^{-2}$ & 4.113 & $3 \times 10^{3}$ \\
\hline-30 & $4.4 \times 10^{-3}$ & $7.7 \times 10^{-3}$ & $1.1 \times 10^{-2}$ & 4.082 & $4 \times 10^{2}$ \\
\hline
\end{tabular}

${ }^{\mathrm{a}}[\mathrm{a}]=\left[\mathrm{CH}_{3} \stackrel{+}{\mathrm{C}}_{\mathrm{H}}\right] ; \quad[\mathrm{b}]=\left[\mathrm{CH}_{3} \mathrm{OCH}_{2} \mathrm{OCH}_{3}\right] ; \quad[\mathrm{c}]=\left[\mathrm{CH}_{3} \mathrm{OCH}_{2} \stackrel{+}{\mathrm{O}}-\mathrm{CH}_{3}\right]$

b As given by computer, $\pm 10^{-3} \mathrm{ppm}$.

c $\Delta H_{\mathrm{ea}}=-5 \pm 2 \mathrm{kcal} \mathrm{mol}^{-1} ; \Delta S_{\mathrm{ea}}=-8 \pm 2 \mathrm{cal} \mathrm{mol}^{-1} \mathrm{deg}^{-1}$.

and since

$$
K_{\mathrm{em}}=\frac{[17 \mathrm{e}]}{[17 \mathrm{a}][17 \mathrm{c}]},[17 \mathrm{a}]=\frac{[17 \mathrm{e}]}{[17 \mathrm{c}]} \cdot \frac{1}{K_{\mathrm{em}}} ;
$$

and, eventually (substituting from eq 20 ):

$$
[17 \mathrm{a}]=\frac{1}{K_{\mathrm{em}}} \frac{\delta-\delta_{\mathrm{c}}}{\delta_{\mathrm{e}}-\delta}
$$

\section{b. Determination of [17d] and [17b] ( $c f$. eq 18)}

Since :

$$
\begin{aligned}
& {[17 \mathbf{a}]_{0}=[17 \mathbf{a}]+[17 \mathbf{d}]+[17 \mathrm{e}]} \\
& {[17 d]=[17 \mathbf{a}]_{0}-[17 \mathbf{a}]-[17 \mathrm{e}]} \\
& =[17 \mathbf{a}]_{0}-[17 \mathbf{a}]-\left([17 \mathbf{c}]_{0}-[17 \mathbf{c}]\right)
\end{aligned}
$$

and, eventually (substituting from eq $20 \mathrm{a}$ and 21 ):

$$
\begin{aligned}
{[17 \mathrm{~d}]=[17 \mathrm{a}]_{0} } & -\frac{1}{K_{\mathrm{em}}} \frac{\delta-\delta_{\mathrm{c}}}{\delta_{\mathrm{e}}-\delta} \\
& -\left([17 \mathrm{c}]_{0}-[17 \mathrm{c}]_{0} \frac{\delta_{\mathrm{e}}-\delta}{\delta_{\mathrm{e}}-\delta_{\mathrm{c}}}\right)
\end{aligned}
$$

c. Determination of [17b] (cf. eq 18):

$$
[\mathbf{1 7 b}]=[1 \mathbf{1 7 b}]_{0}-[\mathbf{1 7 d}]
$$

[17d] from eq 23.

Thus, we have [17a], [17b], and [17d], required to determine $K_{\text {ea }}$ (eq 18), from eq 21,23 , and 24 , respectively.

The knowledge of the following chemical shifts is required:

$\delta$, resulting, observed chemical shift of $\mathrm{CH}_{3} \mathrm{O}$, for exchanging 17c and 17e; $\delta_{c}$, chemical shift of $\mathrm{CH}_{3} \mathrm{O}$ in $17 \mathrm{c} ; \delta_{\mathrm{e}}$, chemical shift of $\mathrm{CH}_{3} \mathrm{O}^{+}$in $17 \mathrm{e}$, determined independently, in the studies of equilibria, involving 17a and 17c.

Thus, if we consider $\mathrm{CH}_{3} \mathrm{OCH}_{2} \mathrm{OCH}_{3}$, as a model of the growing chain of polyacetal (e.g., polydioxolane) at the concentration $\left.\mathrm{fOCH}_{2} \mathrm{CH}_{2} \mathrm{OCH}_{2}\right\}$ $=1.0 \mathrm{~mol}^{-1}$, then the ratio of the oxonium ions to carbenium ions would be equal to: $3 \times 10^{3}$ (i.e., $0.03 \%$ of carbenium ions). Although this is a very rough approximation, but at least gives for the first time an estimation of the position of equilibria between oxonium ions and carbenium ions in the polymerization of cyclic acetals.

However, before the reactivities of both kinds of ions ( $c f$. scheme 10) are known the question whether the small fraction of carbenium ions or the overwhelming fraction of oxonium ions is responsible for the chain growth cannot be answered (cf. again scheme 10). This is treated in the next section.

\section{RATE CONSTANTS OF REACTION OF ETHERS AND ACETALS WITH CARBENIÚM AND OXONIUM IONS ${ }^{18}$}

Propagation in the polymerization of cyclic acetals, proceeding according to scheme 10 simultaneously on the macrocarbenium and macrooxonium ions is kinetically similar to the propagation on any other pair of growing species simultaneously present and exchanging like macroions and macroion-pairs ${ }^{19}$ or macroion-pairs and macroesters. ${ }^{20}$ However, since the concentration of the 
growing species in the polymerization of cyclic acetals is low and there is a fast exchange between the carbenium and oxonium ions, we could not find, at least till now, any method of kinetic treatment of the polymerizing system, giving us an access to $k_{\mathrm{pc}}$ and $k_{\mathrm{pox}}$ (rate constants of propagation on carbenium and oxonium ions respectively, $c f$. scheme 10). Thus, in this section we summarize our recent studies of the model systems, permitting to determine rate constants of reactions of carbenium and oxonium ions which have structures similar to these expected in the polymerization of cyclic acetals. On the other hand, these reactions have been studied with a linear acetal, modelling the polymer segment ( $c f$. again scheme 10 ) or monomer molecule.

The system is:

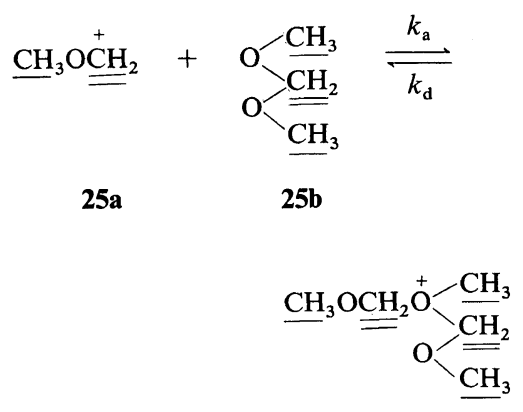

$25 c$

The oxonium ion $25 \mathrm{c}$ can also react with dimethoxymethane, in the exchange process:

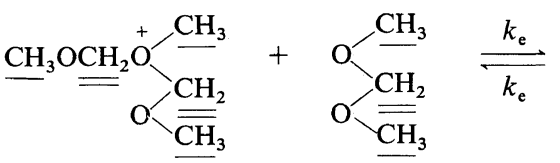

$$
\begin{aligned}
& 25 \mathrm{c} 25 \mathrm{~b}
\end{aligned}
$$

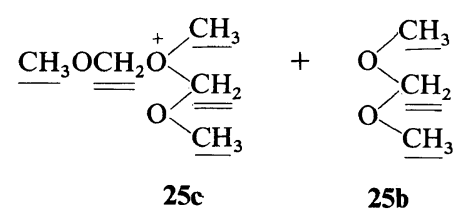

where:

for $\underline{\mathrm{CH}}_{2}$ groups. Thus, $\mathrm{CH}_{3}$ and $\underline{\mathrm{CH}}_{2}$ groups, coming from three different compounds are exchanging (25a, 25b, and 25c). The lifetime of the oxonium ion $25 \mathrm{c}$ is given by the rate of dissociation into components $\left(k_{\mathrm{d}}\right)$ and the rate of exchange $\left(k_{\mathrm{e}}\right)$. These reactions demonstrate their presence in ${ }^{1} \mathrm{H}$ NMR for both $\mathrm{CH}_{3}$ and $\mathrm{CH}_{2}$ groups, because the methyl and methylene groups originally coming from methoxymethylium cation 25a exchange with the corresponding groups in dimethoxymethane $25 b$.

Thus, we have

$$
1 / \tau_{\mathrm{ox}}=k_{\mathrm{d}}+k_{\mathrm{e}}[25 \mathrm{~b}]
$$

However, using a sufficiently large excess of $\mathbf{2 5 b}$ we can eliminate contribution of $\mathrm{CH}_{3} \mathrm{O}^{+} \mathrm{CH}_{2}$ to the chemical shifts, because proportions of 25a left in solution becomes sufficiently small ( $c f$. Table V). From the view point of treatment of the exchange we can apply equations of dynamic ${ }^{1} \mathrm{H}$ NMR for $\mathrm{A} \rightleftharpoons \mathrm{B}$ fast exchange. ${ }^{21}$ Since both methylene groups are similar in 25c (in contrast to methyl groups) it is easier to use these groups for kinetic treatment. Thus:

$$
\frac{1}{\tau_{\mathrm{ox}}}=2 \times \frac{4 \Pi f_{25 \mathrm{c}} f_{25 \mathrm{~b}}^{2} \Delta v^{2}}{S-S_{0}}
$$

$$
\begin{aligned}
f_{25 c} & =\frac{2[25 c]}{2[25 c]+[25 b]} \\
f_{25 b} & =\frac{[25 b]}{2[25 c]+[25 b]}
\end{aligned}
$$

(factor 2 comes from the fact that in the oxonium ion $25 \mathrm{c}$ there are two equivalent methylene groups, exchanging with one methylene group in dimethoxymethane).

$\Delta v=\delta_{25 \mathrm{c}}-\delta_{25 \mathrm{~b}}$ (i.e., difference in chemical shifts of methylene groups in $25 \mathrm{c}$ and $25 \mathrm{~b}, \mathrm{~s}^{-1}$ ); $S$ is the signal width at the one half of its height, $\mathrm{s}^{-1}$; $S_{0}=f_{25 \mathrm{c}} S_{25 \mathrm{c}}+f_{25 \mathrm{~b}} S_{25 \mathrm{~b}} \approx 1 \mathrm{~s}^{-1}$ (the weighed average of the widths of signals of methylene groups at the one half of their heights).

In order to construct a plot of $1 / \tau_{\text {ox }}$ as a function of [25b] (eq 26), leading to $k_{\mathrm{d}}$ and $k_{\mathrm{e}}$, we have to know the following values.

- Equilibrium concentrations of dimethoxymethane ([25b]) and oxonium ion ([25c]), for determining $f_{25 \mathrm{c}}$ and $f_{25 \mathrm{~b}}$, required in eq 27 
and [25b] directly in eq 26,

$-\delta_{25 \mathrm{c}}$ and $\delta_{25 \mathrm{~b}}$, i.e., chemical shifts of methylene groups in $\mathbf{2 5 c}$ and $\mathbf{2 5 b}$.

The equilibrium concentrations were calculated on the basis of the starting concentrations and the equilibrium constant $K_{\mathrm{ea}}$ (determination described in the previous paragraph),

$$
K_{\mathrm{ea}}=\frac{[25 \mathrm{c}]}{[25 \mathrm{a}][25 \mathrm{~b}]}=\frac{[25 \mathrm{~b}]_{0}-[25 \mathrm{~b}]}{\left([25 \mathrm{a}]_{0}-[25 \mathrm{~b}]_{0}+[25 \mathrm{~b}]\right)[25 \mathrm{~b}]}
$$

from eq 30 ,

$[25 \mathbf{b}]^{2}-\left([25 \mathbf{b}]_{0}-[25 \mathbf{a}]_{0}-\frac{1}{K_{\text {ea }}}\right)[25 \mathbf{b}]-\frac{[25 \mathbf{b}]_{0}}{K_{\text {ea }}}=0$

and eq 31 permitted to calculate [25b] for various temperatures, by using the known starting concentrations and $K_{\text {ea }}$ for a given temperature.

Concentration of $\mathbf{2 5 c}$ is given by

$$
[25 c]=[25 b]_{0}-[25 b]
$$

In Table $\mathrm{V}$ several sets of numerical data needed for constructing of the plot according to eq 26 and leading to $k_{\mathrm{d}}$ and $k_{\mathrm{e}}$ are given.

$\delta_{25 \mathrm{~b}}$ and $\delta_{25 \mathrm{c}}$ have been determined directly and equal 4.67 and $5.8 \mathrm{ppm}$ respectively.

Data similar to those given as an example in Table $V$ permitted to calculate $1 / \tau_{\text {ox }}$ and, eventually,

\begin{tabular}{|c|c|c|}
\hline Temp & $k_{\mathrm{d}}$ & $k_{\mathrm{e}}$ \\
\hline${ }^{\circ} \mathrm{C}$ & $\mathrm{s}^{-1}$ & $1 \mathrm{~mol}^{-1} \mathrm{~s}^{-1}$ \\
\hline-70 & $(6.7 \pm 0.6) \times 10^{2}$ & $(1.9 \pm 0.3) \times 10^{4}$ \\
\hline-50 & $(1.6 \pm 0.2) \times 10^{3}$ & $(3.1 \pm 0.7) \times 10^{4}$ \\
\hline
\end{tabular}
to determine $k_{\mathrm{d}}$ and $k_{\mathrm{e}}$ :
Since $k_{\mathrm{a}}=K_{\mathrm{ea}} k_{\mathrm{d}}, k_{\mathrm{a}}$ could also be calculated; thus, at $-70^{\circ} \mathrm{C} k_{\mathrm{a}}=2 \times 10^{6} 1 \mathrm{~mol}^{-1} \mathrm{~s}^{-1}$.

Now, we can compare two second order rate constants: $k_{\mathrm{a}}$ and $k_{\mathrm{e}}$, characterizing the rates of reaction of the linear acetal with carbenium ion and with oxonium ion, which is constructed from the same carbenium ion and the linear acetal serving simultaneously as a model of reacting monomer. The carbenium ion reacts faster, as it could have been expected, but at $-70^{\circ} \mathrm{C}$ only $10^{2}$ times. This difference not as large as expected, is due to the inherent instability of the oxonium ion, when a weak nucleophile, like linear acetal, participates in the oxonium ion formation.

Having in our disposal $K_{\mathrm{ea}}, k_{\mathrm{a}}$, and $k_{\mathrm{e}}$ we can now estimate the contribution of the carbenium ion and oxonium ion in the polymerization of cyclic acetals, providing that the propagation according to scheme 10 is adequately described by eq 25 and 26 . In other words, we assume that the corresponding rate constants are simultaneously proportional.

Thus, if we have [polymer] $\approx[$ monomer] $\approx 1 \mathrm{~mol}$ $1^{-1}$, then it follows from $K_{\text {ea }} \sim 10^{3}$ (at $-70^{\circ} \mathrm{C}$ ), that less than $0.1 \%$ of ions are carbenium ions. Thus, since $k_{\mathrm{a}} / k_{\mathrm{e}} \approx 10^{2}$, above $90 \%$ of monomer addition in propagation should proceed on oxonium ions. With increasing temperature the concentration of carbenium ions would increase, but the ratio $k_{\mathrm{a}} / k_{\mathrm{e}}$ would decrease $\left(\Delta H_{\mathrm{e}}^{\neq}>H_{\mathrm{a}}^{\neq}\right)$and the contributions of carbenium and oxonium ions should not dramatically change, unless the temperature is so raised that the side reactions start to become important (e.g., $\mathrm{H}^{-}$transfer to carbenium ion, being important above $-20^{\circ} \mathrm{C}$ ).

Table V. Numerical values needed for construction of the

\begin{tabular}{|c|c|c|c|c|c|c|c|}
\hline & $K_{\text {ea }}$ & {$[25 \mathrm{a}]_{0}$} & {$[25 \mathbf{b}]_{0}$} & $S$ & {$[25 c]$} & {$[25 \mathbf{b}]$} & $1 / \tau_{\text {ox }}$ \\
\hline & $1 \mathrm{~mol}^{-1}$ & $\operatorname{mol} 1^{-1}$ & $\operatorname{mol~1} 1^{-1}$ & $\mathrm{~s}^{-1}$ & $\mathrm{~mol} \mathrm{l}^{-1}$ & $\mathrm{~mol}^{-1}$ & $\mathrm{~s}^{-1}$ \\
\hline-70 & $3 \times 10^{3}$ & $\begin{array}{l}3.6 \times 10^{-3} \\
4.5 \times 10^{-2}\end{array}$ & $\begin{array}{l}1.1 \times 10^{-2} \\
9.1 \times 10^{-2}\end{array}$ & $\begin{array}{r}18.4 \\
6.7\end{array}$ & $\begin{array}{l}3.5 \times 10^{-3} \\
4.4 \times 10^{-2}\end{array}$ & $\begin{array}{l}7.5 \times 10^{-3} \\
4.6 \times 10^{-2}\end{array}$ & $\begin{array}{r}852 \\
1556\end{array}$ \\
\hline-50 & $1 \times 10^{3}$ & $\begin{array}{l}3.6 \times 10^{-3} \\
1.6 \times 10^{-2}\end{array}$ & $\begin{array}{l}1.1 \times 10^{-2} \\
3.2 \times 10^{-2}\end{array}$ & $\begin{array}{r}10.2 \\
6.1\end{array}$ & $\begin{array}{l}3.2 \times 10^{-3} \\
1.5 \times 10^{-2}\end{array}$ & $\begin{array}{l}7.7 \times 10^{-3} \\
1.7 \times 10^{-2}\end{array}$ & $\begin{array}{l}1680 \\
1866\end{array}$ \\
\hline
\end{tabular}
plots according to eq 26 (see text) 


\section{REFERENCES}

1. K. Hiraoka and P. Kebarle, J. Am. Chem. Soc., 99, 360 (1977).

2. S. Słomkowski and S. Penczek, J. Chem. Soc., Perkin Trans., 2, 1718 (1974).

3. S. Penczek, Macromol. Chem., 175, 1217 (1974).

4. E. M. Arnett, in "Progress in Physical Organic Chemistry," Vol. 1, S. G. Cohen, A. Streitwieser, Jr., and R. W. Taft, Ed., Interscience Publishers, New York, N. Y., and London, 1963, p 223.

5. M. Bjorøy, B. B. Saunders, S. Esperas, and J. Songstad, Phosphorus, 83 (1976).

6. K. Brzezińska, W. Chwiałkowska, P. Kubisa, K. Matyjaszewski, and S. Penczek, Makromol. Chem., 178, 2491 (1977).

7. K. Matyjaszewski, P. Kubisa, and S. Penczek, Preprints, IUPAC 26th International Symposium on Macromolecules, Mainz, September 17-21, 1979, I, 161.

8. V. M. DePalma, Y. Wang, and L. M. Dorfman, J. Am. Chem. Soc., 100, 5416 (1978).

9. L. M. Dorfman, Y. Wang, H.-Y. Wang, and R. J. Sujdak, Faraday Discuss. Chem. Soc., No. 63, 149 (1977).

10. C. B. Kim and K. T. Leffek, Can J. Chem., 53, 3408 (1975).
11. G. A. Olah, J. Sommer, and E. Namanworth, J. Am. Chem. Soc., 89, 3576 (1967).

12. R. J. Sujdak, R. L. Jones, and L. M. Dorfman, J. Am. Chem. Soc., 98, 4875 (1976).

13. H. Meerwein, V. Hederich, H. Morschel, and K. Wunderlich, Annalen, 635, 1 (1960).

14. S. Słomkowski and S. Penczek, Chem. Commun., 1347 (1970).

15. Z. Jedliński, J. Łukaszczyk, J. Dudek, and M. Gibas, Makromolecules, 9, 621 (1976).

16. Kabir-ud-Din and P. H. Plesch, J. Chem. Soc., Perkin Trans., 2, 937 (1978).

17. F. Afshar-Taromi, M. Scheer, P. Rempp, and E. Franta, Macromol. Chem., 179, 849 (1978).

18. R. Szymański and S. Penczek, in preparation.

19. M. Szwarc, "Ions and Ion Pairs in Ionic Polymerization" in "Ions and Ion Pairs in Organic Reactions," Vol. 2, M. Szwarc, Ed., WileyInterscience, New York, N.Y., London, Sydney, and Toronto, 1974, p 375.

20. S. Penczek and K. Matyjaszewski, J. Polym. Sci., Polym. Symp., 56, 255 (1976).

21. G. Binsch, "Band-Shape Analysis" in "Dynamic Nuclear Magnetic Resonance Spectroscopy,” L. M. Jackman and F. A. Cotton, Ed., Academic Press, New York, N.Y., San Francisco, and London, 1975, p 50. 